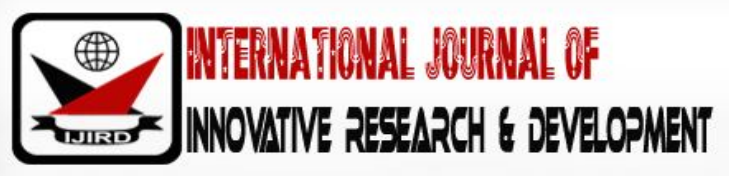

ISSN 2278 - 0211 (Online)

\section{Deflocculating Capabilities of Musa Paradisiaca Peels Ash in Ceramics Clay Slip Preparation}

\author{
Enoidem N. A. Udoh \\ Senior Lecturer, Department of Fine and Industrial Arts, University of Uyo, Nigeria \\ Clement Etim Ekong \\ Senior Lecturer, Department of Fine and Industrial Arts, University of Uyo, Nigeria
}

\begin{abstract}
:
The skillful manipulation of resources can encourage interest in further researches. It can result in ultimate benefits and can lead to discovery of limitless beneficial and lucrative possibilities. This could be found through local experiment by emulating the first principles. In ceramics, for instance, casting slip is generally prepared by the use of electrolytes like Calgon, Sodium Silicate and Sodium Carbonate for deflucculation. These materials can sometimes be relatively costly, and non-available depending on locations. In such situations, local substitutes become imperative. It is on this premise that this research was undertaken. In the research, Musa Paradisiaca (plantain) a local plant edible in its green unripe or ripe state was used. A series of experiments was conducted with it using the dry peelings of its fruits, while the fruits were spared for domestic consumption. The dried peelings were burnt to ashes. The ash was collected, made into solution and filtered properly in a 200 mesh. The solution was used in varying proportions as an active deflocculant. The result was rewarding as it was found that the ashes of Musa Paradisiaca Peels Ash was a dependable substitute for sodium carbonate in casting slips. Therefore, Musa Paradisiaca Ash solution or ash is recommended for use in ceramics slip preparation.
\end{abstract}

Keywords: Deflocculating, slip preparation, plantain peels, Musa Paradisiaca

\section{Background}

Plantain (Musa Paradisiaca) is a member of the genus, Musa. Like all members of the genus, it is indigenous to the tropical and subtropical countries; and had been around for over 400 years (Alabi, A. S; Omotoso, G. O; Enaite, B. U; Akinola, O. B and Tagoe, N. B; 2013). Plantain has a number of varieties which are staples in most tropical regions of the world. In Nigeria, Musa paradisiaca is cultivated mainly in the rain forest regions - southern and western regions. Its peelings have been used in many societies for different purposes. Some people blend the dried ground peelings with yam flour as one of their stable foods. The meal is known to have healing effects on patients with gastric pains or ulcer. Plantain as food can be prepared in a variety of ways. It can be Prepared as soup, sauce, broth or porridge; and can equally be roasted. It can be served cold, warm or hot.

The leaves are used as foils for wrapping items, while the fibre extracted from the soft stem are used in various ways where natural fibre is a requirement. It is also used as sponge for bathing and washing. Its ash, sap and liquid are used for its antifungal and general curative properties (Jimmy, 2016; Mkpenghe, 2017). The chemical contents of the peelings are able to inhibit the growth of fungi or kill it completely. This is traceable to its antibacterial and anti-inflammatory properties.

The most interesting and, perhaps, thought provoking use of plantain seems to be the use of its peels. Musa paradisiaca peels have been used extensively in soap making by the natives of Southern Nigeria. It has also been used as an ingredient for broths, sauces and soups. Even more thought provoking, is its use for the preparation of ester. It is often used in palm oil to create ester for eating roasted yam, cocoa yam, plantain, dried cod fish and dried fish delicacy preparations.

Recently, the researchers have discovered the peels of plantain as a dependable softener and catalyst for cooking cow peas. However, trying it capabilities on deflocculating clay particles in slip preparation was the focus of this study. It was inspired by the oil dispensing and consequent ester forming capabilities of plantain peels solution. Undoubtedly, the quantity of soda and other deflocculants required in casting slip preparation is small, about $3 \%$ compared to clay and water which is about $60 \%$ and $33 \%$, respectively. These deflocculants are all imported. Therefore, in view of the current trend in Nigeria where government is trying to ban importation of goods and materials, its constant availability may not be guaranteed. Thus, 
it becomes necessary to explore substitutes. Besides being more reliable to be self sufficient, the cost effectiveness of using plantain peels for slip deflocculation should be an added advantage for ceramists within and outside Nigeria.

Although there is no complete ban on importation of sodium compounds yet, there is a constant rising cost of sodium carbonate $\left(\mathrm{Na}_{2} \mathrm{CO}_{3}\right)$ in Nigerian markets. This is a hindrance to casting slip preparation at the local level. Therefore, the need to subsidize it with as many local materials as possible cannot be over emphasized, especially, now that there is a growing demand for at least $80 \%$ of local content in the manufacturing sector in the Nigerian Economy, for self reliance.

The aim of the study, therefore, was to determine the possibility of preparing casting slip using Musa Paradisiaca Ash Solution (Plantain Peels Ash Solution [PPAS]) as a deflocculant. The objectives were:

- To determine the effectiveness of casting slip prepared using Musa Paradisiaca Ash Solution (Plantain Peels Ash Solution [PPAS]) as a deflocculant

- To determine the efficiency of the cast product using PPAS against those cast with slip prepared using conventional deflocculants alone.

- To determine the cost effectiveness of slip prepared using PPAS as a deflocculant.

The following research questions were raised to aid in finding solutions to the problems associated with the experiment;

- Can Musa paradisiaca be utilized to obtain a casting slip?

- Can slip deflocculated with Musa paradisiaca be as effective as the one deflocculated with conventional deflocculants?

- $\quad$ Can casting slip deflocculated with Musa paradisiaca peels be cost effective?

\subsection{Relevance of the Study}

This study will be useful in studio and industrial ceramics practice. It will equally be useful in areas where plant or natural deflocculants are a requirement. It will create employment as the services of youths, fresh graduates and other unemployed would be needed from the point of sourcing the materials, extraction to actual application.

\subsection{Conceptual Framework}

This study was anchored on the concept of thixothropy. This is the staying power of some liquids, the property of a liquid to become more viscous when static (Scott, 1998:188), when not stirred, shaken or disturbed. Thixothropy makes it possible for the casting slip to take and retain the cast form in the mould. This property is equally dependent on the electrolytes which cause the electrolytic action to keep the particles afloat. This was exploited for the deflocculation of clay slop.

\subsection{Materials and Procedure}

The study was Studio Practice based, generally referred to action research. For action research, theory informs practice, practice refines theory, in a continuous transformation. In any setting, people's actions are based on implicitly held assumptions, theories and hypotheses, and with every observed result, theoretical knowledge is advanced. The two are intertwined aspects of a single change process. It is up to the researchers to make explicit the theoretical justifications for the actions, and to question the basis of those justifications. The ensuing practical applications that follow are subjected to further analysis, in transformative cycles that continuously alternates emphasis between theories and practice (O'Brien, 2001 cited in Auriacombe, 2015).

In course of the investigation, three related experiments were undertaken. The materials and apparatus used included weighing balance, firing chamber, combustion pan (large shallow steel tray), a set of sieve/ mesh, beaker, tripod stand, unripe plantain (musa paradisiaca) peels.

Unripe plantain peels were collected from Uyo metropolis in Akwa Ibom State, Nigeria. They were exposed to the sun, for fourteen days, to dry. The dried peels were placed in an open combustion pan placed on a tripod stand and heated till the peels ignited fire. The ignition temperature was between $150^{\circ} \mathrm{C}$ and $200^{\circ} \mathrm{C}$. A metal rod with a wooden handle was used to turn the burning peels in order to ensure uniform combustion and subsequent burning to ash. The ashing lasted three hours. A slurry of the ashed sample was prepared by adding $0.15 \mathrm{~kg}$ of the ashes to $2.5 \mathrm{dm}^{3}$ of distilled and deionized water.

Kuye and Okorie (1990) as cited in Onyegbado, Iyagba and Offor (2016) showed that particle size of 1.06 x 10-4m give the highest concentration of potassium hydroxide when slurry of the ashed sample containing $0.15 \mathrm{~kg}$ of the ashes in $2.5 \mathrm{dm}^{3}$ of distilled and deionized water was kept for eight hours at $60^{\circ} \mathrm{C}$. In this study, borrowing a leaf from Onyegbado, Iyagba and Offor (2016) slurry prepared under the same condition was kept for forty-eight hours in a further attempt to ensure maximum enhancement of the alkali content of the ash. Subsequently, the slurry was filtered through a 200 mesh. It is worthy of note that the potash content in the peels of some varieties of Nigerian grown plantain and banana ranges from 69.0 to $81.9 \%$ of ash and 4.7 to $9.6 \%$ of dry peel (Babayemi et al, 2010).

\section{The Plantain Peel Ash Experiment}

An experiment to determine the suitability of Plantain Peel Ash (PPA) as slip deflocculants or suspender was proposed by Dr. Enoidem N. A. Udoh of Ceramics Unit of the Department of Fine and Industrial Arts, University of Uyo, Uyo, Nigeria. The following procedures and steps were taken. 


\subsection{Experiment 1}

\subsubsection{Objective}

To collect plantain peels ash

\subsubsection{Equipment and Materials \\ Open tray, Plantain peels}

\subsubsection{Procedure}

\section{- Step I}

Plantain peels were collected from unripe plantains and sundried. The dried-out peels were then burnt to ashes in an open tray to allow for sufficient oxygen to aid the combustion process. The Ash was spread out in the open to allow for proper cooling.

- $\quad$ Step II

The burnt-out plantain peel ash was collected from the tray and placed in a bottle. On collection, the ash was found to be highly hygroscopic (exhibiting deliquescence), forming a thick aqueous solution with water drawn from the atmosphere, the solution exhibited black colouration. The total weight of what was collected was $600 \mathrm{~g}$.

- $\quad$ Step III

$10 \mathrm{ml}$ of water was added to the aqueous solution to enhance its fluidity. The total weight of the solution became 610 grams. This solution of plantain peels ash and water was used as, Plantain Peels Ash (PPA), for subsequent experiments.

\subsection{Experiment 2}

\subsubsection{Objective}

To test for the efficiency of PPA as a deflocculant

\subsubsection{Equipment and Materials}

Five small plastic containers of 1 liter in volume each, prepared clay slop.

\subsubsection{Procedure}

- $\quad$ Step I

200 grammes of prepared clay slop with a density of 1.53 were measured into 5 separate plastic containers. The containers were labeled batch 1, 2, 3, 4 and 5, respectively.

- $\quad$ Step II

Using a syringe, $1 \mathrm{ml}$ of Plantain Peels Ash solution was measured and added to the plastic container labeled batch 1. The mixture was stirred vigorously for 3 minutes.

- $\quad$ Step III

$2 \mathrm{ml}$ of PPA solution was measured and added to the clay slop in the container labeled, Batch 2 and vigorously for 3 minutes.

- $\quad$ Step IV

$3 \mathrm{ml}$ of PPA was added to the clay slop in the container labeled, batch 3 and stirred vigorously for 3 minutes.

- Step V

$4 \mathrm{ml}$ of PPA solution was added to the clay slop in the container labeled, batch 4 and stirred vigorously for 3 minutes.

- Step VI

$5 \mathrm{ml}$ of PPA solution was added to the clay slop in the container labeled, batch 5 and stirred vigorously for 3 minutes.

\subsubsection{Observation}

It was observed that on addition of the PPA solution, clay particles in the slurry flocked together to form a paste. So, rather than dispersing the particles in clay slop, PPA solution suspended the clay particles, and bounded them one to the other. The Bonding and paste formed, thickened as the quantity of PPA solution increased. Thus, Batch 5 was seen to be a stiff hard past, while Batch 1 was the lightest and most fluidity.

\subsubsection{Inference}

PPA solution was found to be a suitable deflocculant for suspension of clay particles in slips. The quantities of PPA used in all five batches were also seen to be excessive. A second experiment was, therefore, necessary to determine the suitability of PPA solution as a suspender. The experiment was to use smaller ratios of PPA solution to the clay slop. $\mathrm{NaSiO}_{3}$ was also to be used as deflocculant so as to disperse the clay particles in the slop. 


\subsection{Experiment 3}

\subsubsection{Objective}

To determine the suitability of PPA solution as suspenders in slip preparation

\subsubsection{Equipment and Materials}

$\mathrm{NaSiO}_{3}$, clay slop, plastic containers

\subsubsection{Procedure}

- $\quad$ Step 1

$1200 \mathrm{~g}$ of clay slop was measured into a beaker. $3 \mathrm{ml}$ of $\mathrm{NaSiO}_{3}$ was added and stirred vigorously for 5 minutes to form and unsuspended deflocculated clay slip.

- $\quad$ Step II

The resulting unsuspended deflocculated clay slip was divided into three equal parts of $400 \mathrm{~g}$ each. These were held in three plastic containers. The containers were labeled, batch 1,2 and 3, respectively.

- $\quad$ Step III

The three batches of sample were treated with PPA Solution as follows:

- $0.5 \mathrm{ml}$ of PPA solution was added to the unsuspended deflocculated clay slip labeled batch 1 and stirred vigorously for 3 minutes.

- $1 \mathrm{ml}$ of PPA solution was added to the unsuspended deflocculated clay slip labeled batch 2 and stirred vigorously for 3 minutes and

- $\quad 1.5 \mathrm{ml}$ of PPA solution was added to the unsuspended deflocculated clay slip labeled batch 3 and stirred vigorously for 3 minutes.

- $\quad$ Step IV

$0.5 \mathrm{ml}$ of $\mathrm{NaSi}_{3}$, was then added to each of all the three batches. Each batch was stirred vigorously for another 3 minutes. Step IV was necessary because it was found through Experiment 3 that PPA, as a deflocculant, is best suited as a substitute for suspension of slip.

\subsubsection{Observation}

The addition of PPA to the clay slip reduced the fluidity of the slip by causing the clay particles to flock together. The fluidity decreased as the quantity of PPA solution added increased. Thus, Batch 1 was seen to be more fluidly than Batches 2 and 3. However, the addition of $0.5 \mathrm{ml}$ of $\mathrm{NaSiO}_{3}$, restored the fluidity of batches 2 and 3 making them useable as casting slips, and made batch one more fluidly.

All three batches were used for casting. Three different plaster moulds were used interchangeably.

\section{Results}

All samples cast with the prepared slips were successful. Samples taken from the moulds did not exhibit any trace of flabbiness. Neither were they found to be brittle on drying. On the contrary, they were found to exhibit increased green strength.

\subsection{Inference}

From the foregoing results, it can be inferred that the use of Plantain Peels Ash (PPA) as a deflocculant in casting slips:

- Increases suspension of clay particles

- Increases thixothropy

- Reduces the casting and drying time of cast pieces

- Increases the green strength of cast pieces

Sample 3 from the above experiments was adopted as the studio slip recipe in Domoseh Studio. It was also used in Ceramics Unit, Department of Fine and Industrial Arts, University of Uyo, Uyo, Nigeria.

\section{Summary, Recommendations and Conclusion}

Slips which met the required standard of Studio and Industrial casting needs were produced. This was done bearing in mind that Ekong and Azubuike (2016) observe that there are some variables that influence deflocculation of clays. These include change of water supply, alkalinity of water, additives such as chlorine in the water, humidity and temperature of the environment and the plasticity of the clay used. Substantial amounts of slip deflocculants are required in the country for studio and industrial ceramics practice. Vegetable matter has proved to be a potential source of material for deflocculation of casting slip. Therefore, it is recommended that Plantain Peels Ash (PPA) solution be used as a replacement for the imported slip suspenders. Slips deflocculated with PPA solution produced similar results with those deflocculated with a conventional material, Sodium Carbonate $\left(\mathrm{NaCO}_{3}\right)$ which was used as the control in the experiment. The slip showed dependable cost 
effectiveness especially in developing countries such as Nigeria. An alternative like this should be vigorously and sincerely encouraged.

\section{Suggestions for Further Studies}

- $\quad$ PPA should be analyzed so as to ascertain the active ingredients that are responsible for deflocculation of slip.

- Other parts of plantain plant should be tried for this or similar purposes.

- $\quad$ Plantain ash should be exploited for glaze formulations.

- Plants which contain similar elements such as palm tree should be tried in similar ways.

\section{Acknowledgments}

The researchers are grateful to Domoseh Studios who allowed the use of their facilities for the experiments. The Studio Manager, Mr. Isaac is commended for his keen recording of the procedures of the three successive experiments. The research assistants, Emmanuel Umoh and others who contributed in one way or the other to the success of this research are appreciated.

\section{References}

i. Alabi, A. S; Omotoso, G. O; Enaibe, B. U; Akinola, O. B; and Tagoe, N. B. Beneficial effects of Low Dose Musa Paradisiaca on the semen quality of Male Wistar Rats. Niger Med J. (serial online) 2013 (cited 2017 Mar 24); 54: 92-5 Available from: http:/ / www.nigeriamedj.com/ text.asp? 2013/ 54/ 2/ 92/110035.

ii. Auriacombe, C. J (2015) Closing the gap between theory and practice with action research. In: African Journal of Public Affairs (8) 3. Pp 1 - 16.

iii. Babayemi, J. O., Dauda, K. T., Nwude, D. O. and Kayode, A. A. A. (2010). Evaluation of the Composition and Chemistry of Ash and Potash from various plant materials - A review. Journal of Applied Sciences, 10:1820 - 1824. http:/ / scialert.net/ abstract/ ?doi=jas.2010.1820.1824 Retrieved 22nd August, 2017.

iv. Onyegbado, C. O., Iyagba, E. T. and Offor, O. J. (2002). Solid soap production using plantain peel ash as source of alkali. In:Journal of Applied Sciences and Environmental Management.6(1).Pp 73 - 77. www.bioline.org.br/ request?ja02016 Retrieved 23rd August, 2017.

v. Ekong, C. E. and Azubike, T. C. (2016). Deffloculation of clay bodies prepared with clays from Ikot Ebom Itam for slip cast forms. Journal of Ceramics and Environmental Design (JOCED) University of Port Harcourt. 3(1 \& 2). Pp. 83 - 91.

vi. Jimmy, G. B. (2016). Oral interview. His compound, Afaha Itak. Ikono LGA.

vii. Mkpenghe, U. E. (2017). Oral interview. His Herbal home, Osuk Ediene, Ikono LGA. 